\section{Size judgments of familiar objects from outline figures*}

\author{
COLIN V. NEWMAN \\ University of Birmingham, Birmingham, England
}

The true physical sizes of three familiar objects, each having only one standard size, were recognized within a series of outline figures with an average error of $2.0 \%$. Large individual differences in accuracy of size judgments were found, whereas, within groups of Ss, there were only low correlations between size judgments of the three familiar objects. Results suggested that, as a prerequisite of familiar size acting as a cue to distance, Ss do have some ability to recall the physical sizes of familiar objects when these are not present in vision but are represented as outline figures.

The familiar size of an object has been shown to act as a cue to distance (Epstein, 1967; Gogel, 1964), but typically the experimental situations have been very contrived and Ss have often been explicitly required to examine the familiar objects immediately prior to making visual judgments of distance. The functional validity of the familiar size cue to distance needs to be established in more ecologically valid situations. Moreover, as a prerequisite of familiar size acting as a cue to distance under normal everyday conditions, it should be demonstrated that $S$ s can recall the true physical sizes of familiar objects when the objects are not present in vision and have not recently been handled. Bolles \& Bailey (1956) and McKennell (1960) presented some positive evidence that $S$ s could recall the true physical sizes of familiar objects. In the present experiment, further normative data was collected on the accuracy with which the familiar sizes of objects can be recognized within a series of outline figures which remained constant in height-width ratio but varied in size.

For familiar size to serve as a cue to the relative distances of two or more objects, rather than the absolute distance of a single object, it is more important for Ss correctly to judge the relative sizes of familiar objects rather than their absolute sizes. To test the consistency with which different Ss judged the relative sizes of familiar objects, size judgments of the different familiar objects were correlated with each other. This showed whether, within groups of $\mathrm{Ss}$, there was a consistent tendency for the same Ss either to overestimate or to underestimate the sizes of all familiar objects.

\section{PROCEDURE}

Three series of figures were drawn on three large sheets of cardboard.

*The data reported here was collected at the University of Leicester, England, where the author beld a Social Seience Research Council studentship.
Each series consisted of outline drawings having the same shape as a familiar object, but only one target drawing in a series had physical dimensions identical to those of the familiar object. Other drawings in the series retained a constant height-width ratio but were progressively larger or smaller than the target drawing. Depending upon which familiar object Ss were to view in subsequent experiments (Newman, 1972), each $S$ was presented with 1,2 , or 3 of the series of drawings and asked to indicate which outline figure in the series had physical dimensions exactly equal to the familiar object named by $E$. The degree to which $S$ picked a drawing deviating from the target gave a measure of the extent to which size of the familiar object was misjudged. Details of the outline figures on the cards, the numbers of $\mathrm{Ss}$, and the familiar objects and their physical dimensions are shown in Table 1, with the results.

\section{RESULTS}

Mean errors for size judgments of the three familiar objects are shown in Table 1, expressed in terms of the height dimension only (height-width ratio was constant).

The following Spearman correlation coefficients were obtained for size judgments within groups of Ss: flashlight battery and table-tennis ball, $\mathrm{r}=.469, \mathrm{~N}=84, \mathrm{p}<.01 ;$ flashlight battery and matchbox, $r=.150$, $\mathrm{N}=32, \mathrm{p}>.05$; table-tennis ball and matchbox, $\mathrm{r}=.175, \mathrm{~N}=32, \mathrm{p}>.05$. DISCUSSION

The true physical sizes of three familiar objects were recognized within a series of outline figures with an average error of $2.0 \%$. Large individual differences in accuracy of size judgments were found. The results confirm that, as a prerequisite of familiar size acting as a cue to absolute distance, Ss do have some ability to recall the physical sizes of familiar objects when these are not present in vision but are represented as outline figures. It remains uncertain, however, to what extent familiar size influences perceived size when familiar objects are actually viewed. Experiments by Gogel (1969) and Gogel \& Newton (1969) showed that familiar size only partially determined perceived size when off-sized familiar objects were viewed under reduced conditions of observation. Under conditions of rich information, Fillenbaum, Schiffman, \& Butcher (1965) and Schiffman (1967) found that familiar size was not one of the operative determinants of judged size; conflicting results were obtained by Franklin \& Erickson (1969) and Slack (1956). Difficulties arise in drawing conclusions from these experiments because familiar objects have been used which come in several different physical sizes (e.g., chairs). This may explain one result reported by Franklin \& Erickson (1969), who found that judged distortion of the size of a physically small chair was about twice that of a physically enlarged chair. There is a far higher ecological probability of perceiving small children's chairs than over-sized adults' chairs.

The relatively low correlations for

Table 1

Size Judgments of Familiar Objects Expressed as Mean Height Judgments

\begin{tabular}{|c|c|c|c|c|c|c|c|}
\hline Familiar Object & $\begin{array}{l}\text { Standard } \\
\text { Dimen- } \\
\text { sions, } \\
\text { Height X } \\
\text { (Width) }\end{array}$ & $\begin{array}{c}\text { Number } \\
\text { of } \\
\text { Outline } \\
\text { Figures } \\
\text { in } \\
\text { Series }\end{array}$ & $\begin{array}{c}\text { Range of } \\
\text { Heights }\end{array}$ & $\begin{array}{l}\text { Number } \\
\text { of Ss } \\
\text { Judging } \\
\text { Size }\end{array}$ & $\begin{array}{l}\text { Mean } \\
\text { Height } \\
\text { Judg- } \\
\text { ments } \\
\text { and } \\
\text { SDs (cm) }\end{array}$ & $\begin{array}{c}\text { Mean } \\
\text { Percen- } \\
\text { tage } \\
\text { Error }\end{array}$ & $\begin{array}{c}\text { SD as a } \\
\text { Percen- } \\
\text { tage of } \\
\text { Mean } \\
\text { Judged } \\
\text { Height }\end{array}$ \\
\hline Flashlight Battery & $\begin{array}{l}\text { Rectangle, } \\
5.8 \mathrm{~cm} \mathrm{X} \\
(3.3 \mathrm{~cm})\end{array}$ & 22 & $\begin{array}{l}4.15 \mathrm{~cm} \\
\text { by } .15 \mathrm{~cm} \\
\text { steps to } \\
7.30 \mathrm{~cm}\end{array}$ & 100 & $\begin{array}{l}5.68 \\
\pm .58\end{array}$ & 2.1 & 10.2 \\
\hline Table-Tennis Ball & $\begin{array}{l}\text { Circle, } \\
3.8 \mathrm{~cm} \\
\text { in diam }\end{array}$ & 30 & $\begin{array}{l}1.9 \mathrm{~cm} \\
\text { by } .10 \mathrm{~cm} \\
\text { steps to } \\
4.8 \mathrm{~cm}\end{array}$ & 84 & $\begin{array}{r}3.73 \\
\pm .37\end{array}$ & 1.8 & 9.9 \\
\hline $\begin{array}{l}\text { Matchbox, } \\
\text { "Swan Vesta" } \\
\text { Brand }\end{array}$ & $\begin{array}{l}\text { Rectangle, } \\
7.9 \mathrm{~cm} \mathrm{x} \\
(4.9 \mathrm{~cm})\end{array}$ & 27 & $\begin{array}{l}5.35 \mathrm{~cm} \\
\text { by } .15 \mathrm{~cm} \\
\text { steps to } \\
9.25 \mathrm{~cm}\end{array}$ & 32 & $\begin{array}{l}8.06 \\
\pm .69\end{array}$ & 2.1 & 8.6 \\
\hline
\end{tabular}


size judgments of the three familiar objects suggests that, as a prerequisite of familiar size serving as a cue to relative distance, $S s$ do not show a high degree of consistency in their ability to recall the physical sizes of familiar objects.

Within groups of Ss, there was no marked tendency for the same Ss to overestimate or underestimate the sizes of all familiar objects consistently. This would suggest that familiar size can serve only as a relatively imprecise cue to relative distance, though it remains to be established to what degree familiar size serves as a cue to relative distance when other distance cues are also present. Newman (1972) found that familiar size had some influence on relative distance judgments despite the presence of clearly defined textural information to distance.

\section{REFERENCES}

BOLLES, R. C., \& BAILEY, D. E Importance of object recognition in size constancy. Journal of Experimental Psychology, 1956, 51, 222-225.

EPSTEIN, $w$ Varieties of perceptual learning. New York: McGraw-Hill, 1967. Pp, 21-53.

FILLENBAUM, S., SCHIFFMAN, H. R., \& BUTCHER, J. Perception of off-size versions of a familiar object under conditions of rich information. Journal of Experimental Psychology, 1965, 69, 298-303.

FRANKLIN, S. S. \& ERICKSON, N. L Perceived size of off-size familiar objects under normal and degraded viewing conditions. Psychonomic Science, 1969 , $15,312-313$

GOGEL, W. C. Size cue to visually perceived distance, Psychological Bulletin, 1964. 62, 217-235.

GOGEL, W. C. The effect of object familiarity on the perception of size and distance. Quarterly Journal of Experimental Psychology, 1969, 21, 239-247.

GOGEL, W. C., \& NEWTON, R. E. Perception of off-sized objects. Perception \& Psychophysics, 1969, 5, 7-9.

MCKENNELL, A. C. Visual size and familiar size: Individual differences. British Journal of Psychology, 1960, 51, 27-35.

NEWMAN, $C$, $V$. Familiar and relative size cues, and surface texture as determinants of relative distance judgments. Journal of Experimental Psychology, 1972, in press. SCHIFFMAN, H. R. Size-estimation of familiar objects under informative and reduced conditions of viewing. American Journal of Psychology, 1967, 80, 229-235.

SLACK, C. W. Familiar size as a cue to size in the presence of conflicting cues. Journal of Experimental Psychology, $1956,52,194-198$. 